\title{
Failure to Convert to Back-Up
}

National Cancer Institute

\section{Source}

National Cancer Institute. Failure to Convert to Back-Up. NCI Thesaurus. Code C63189.

Problem associated with a failure to transition from a primary system, component, file, procedure to a backup in response to a failure in the primary item. 